\title{
Noncommunicative Behavior Assessment of Parents during Restorative Dental Procedures Using Verbal and Written Instructions in a Pediatric Dental Setup
}

\author{
Shital Kiran ${ }^{1}$, Nirav Barad ${ }^{2}$
}

\begin{abstract}
Background: Fear in the children is normal during dental treatment procedures, where the child wants to be with his or her parents during treatment procedures, and parental presence comforts the child in the dental operatory. The objective of this study was to decide compliance in entreating parents to endure silence (noncommunicative) while escorting their child into the dental operatory for restorative care and also to know if any variance in parental compliance occurred once verbal instructions were given to parents vs written instructions only.

Materials and methods: Forty parents of aged 4-9 years attending restorative care were selected and divided into two groups. Group I ( $n=$ 20) parents were given verbal instructions only, and in group II $(n=20)$ parents received written instructions only.

Results: Of the 40 (72.5\%) parents, 29 obeyed the instructions to remain silent. No statistical difference was noted in parental compliance to remain silent compared to the verbal instructions only (85\%) vs written instructions only (60\%).

Conclusion: Parents did comply with instructions to remain a silent as well as acted as a passive observer in the operatory when provided either written or verbal instruction.

Keywords: Child behavior, Noncommunicative, Restorative care, Silent chair.

Journal of South Asian Association of Pediatric Dentistry (2021): 10.5005/jp-journals-10077-3049
\end{abstract}

\section{INTRODUCTION}

Pediatric dental care is influenced by a triad consisting of parents, children, and dental team. Parents play a vital role in the dental behavior of a child; therefore, the role of parents in dental treatment remains a topic of interest to pediatric dentists. ${ }^{1-4}$ Presence of parents in the dental operatory has been a debated since ages; however, the matter of parental presence in the operatory has inspired many pediatric dentists, and they have expressed divergent opinions on whether parents should be present in the dental operatory or not during their children's dental treatment. ${ }^{5,6}$

Practitioners used to exclude the parents from their dental operatory in the past. ${ }^{5}$ Nevertheless, there is an increasing viewpoint among clinicians that it is advantageous to have the parents present in the operatory during his or her children's treatment due to their ability to communicate with the child during any clinical procedure. ${ }^{7}$ Parental presence in the operatory also helps to alleviate anxiety and/or fear of the child regarding dental treatment. Pediatric dentists trust that if the parent is present in operatory, they can observe the child's positive behavior throughout the dental treatment and also ease the child whenever required. Traditionally, parents were excluded completely from the operatory because of the overprotective behavior of parents and also interfere during treatment procedures.

Shaw ${ }^{8}$ suggested that parental presence provides a homely environment for the child which plays a key role in dental attitudes of children. But with the inclusion of parents during the child's treatment procedure, the parent must remain silent so that there is no disturbance or barrier created for the establishment of rapport between the child and the dentist for the clinical success of any dental treatment.
${ }^{1}$ Department of Pediatric and Preventive Dentistry, College of Dental Sciences, Amargarh, Bhavnagar, Gujarat, India

${ }^{2}$ Private Practitioner in Pediatric Dentistry, Surat, Gujarat, India

Corresponding Author: Shital Kiran, Department of Pediatric and Preventive Dentistry, College of Dental Sciences, Amargarh, Bhavnagar, Gujarat, India, Phone: +91 7016310949, e-mail: drdpsk@gmail.com

How to cite this article: Kiran S, Barad N. Noncommunicative Behavior Assessment of Parents during Restorative Dental Procedures Using Verbal and Written Instructions in a Pediatric Dental Setup. J South Asian Assoc Pediatr Dent 2021;4(1):3-8.

Source of support: Nil

Conflict of interest: None

Addelston advocated the term "silent chair," where if the parents were accompanying their children into the operatory, they should sit "silent" on the chair. ${ }^{9}$ It is essential to develop a situation in which the positive aspects of the parental presence can be achieved while reducing negative aspects as possible, and this is only possible if the parent remains silent or passive observer in the dental operatory.

The purpose of this study was to determine compliance of parents to remain silent (noncommunicative) during restorative treatment of their child in the dental operatory and to observe for any variance in parental compliance happened after verbal instructions vs written instructions only.

\section{Materials and Methods}

The protocol for this research was permitted by the institutional ethical committee per the Helsinki declarations (Ksd/Dent/5237). A total of 40 parents of healthy 4-9-year-old children who reported

(c) The Author(s). 2021 Open Access This article is distributed under the terms of the Creative Commons Attribution 4.0 International License (https:// creativecommons.org/licenses/by-nc/4.0/), which permits unrestricted use, distribution, and non-commercial reproduction in any medium, provided you give appropriate credit to the original author(s) and the source, provide a link to the Creative Commons license, and indicate if changes were made. The Creative Commons Public Domain Dedication waiver (http://creativecommons.org/publicdomain/zero/1.0/) applies to the data made available in this article, unless otherwise stated. 
to the outpatient of department of pedodontics and preventive dentistry for routine restorative dental treatment were enrolled as participants in the study.

There were no gender, race, or ethnic restrictions in inclusions or exclusions of samples in the study. The inclusion criteria consisted of healthy 4-9-year-old children requiring routine restorative dental treatment with or without any previous dental experiences and the parents who had the ability to read were included. Exclusion criteria included children younger than 4 years old, with special healthcare needs and requiring sedation or the use of the papoose board and also children with definite negative behaviors were excluded from the study.

Parents and all children who met the inclusion criteria were invited to a consultation area, where they were briefed about the study and asked if they would be voluntary to participate. A valid written informed consent was obtained from the parent and the participant, and assent was also obtained from the child. All parents ( $n=40$ ) were randomly divided into 2 groups, namely, group I verbal communications instructions only $(n=20)$ and group II written instructions only $(n=20)$ using simple random sampling method (Flowchart 1).

In both the study groups, parents were given instructions to ensure silence in dental operatory when accompanying their children during routine restorative treatment. Written instructionsonly group received written instructions from the dental assistant for being present in the operatory basically as a passive silent observer. Verbal instruction-only group received the instructions verbally which was reinforced by the dentist. The dental assistant and the dentist were the same in all the instances.

For appropriate written instruction which may be easily understood by every parent, a simple measure of Gobbledygook (SMOG) a reading ability formula was used, ${ }^{10}$ with the intent that written instructions were able to be read by a parent whose reading comprehension level was between the fifth and sixth grade.
The written instructions that were given to the parents is depicted in Figure 1 that had three illustrations: two illustrations with negative role of the parent in the operatory by communicating verbally with the child or dentist during child's treatment. And the remaining one illustration showing the positive role of the parent in the dental operatory when a parent is quiet and watching the child during treatment in the dental operatory. Regarding verbal instructions, the dentist had verbally given instructions to the parents to be a silent, passive observer and also had educated the parents about positive and negative implications of parental presence as well as communication in the dental operatory.

The group receiving verbal instructions was permitted to ask any questions to the dentist before being seated in the operatory. The group receiving the written instructions only was permitted to ask the dental assistant questions before entering the operatory. The dental assistant only answered direct questions and provided no elaboration. As a customary, dentist answered any questions regarding the planned dental treatment prior to entering the dental operatory.

The dentist can provide two types of responses when a parent did not remain silent. If the parent had interrupted child or dentist during the child's treatment, the dentist's response was: "As indicated in the instructions, verbal interruptions during treatment have a potentially negative effect on your child's care. I encourage you to be a silent watcher or passive observer." If a parent had a question during the child's restorative treatment, the dentist's response was: "As indicated in the instructions, verbal interruptions during treatment have a potentially negative effect on your child's care. I will answer all of your questions at the end of the treatment. I encourage you to be a silent watcher." Each parent was taken to the dental operatory, where they were positioned in a seat to the side and near the end of the dental chair in which the child was seated. After local anesthesia was administered, procedures such as intracoronal restorations and stainless-steel crowns were performed. A rubber dam was routinely used for restorative

Flowchart 1: Study enroliment flow diagram. STROBE, Strengthening the reporting of observational studies

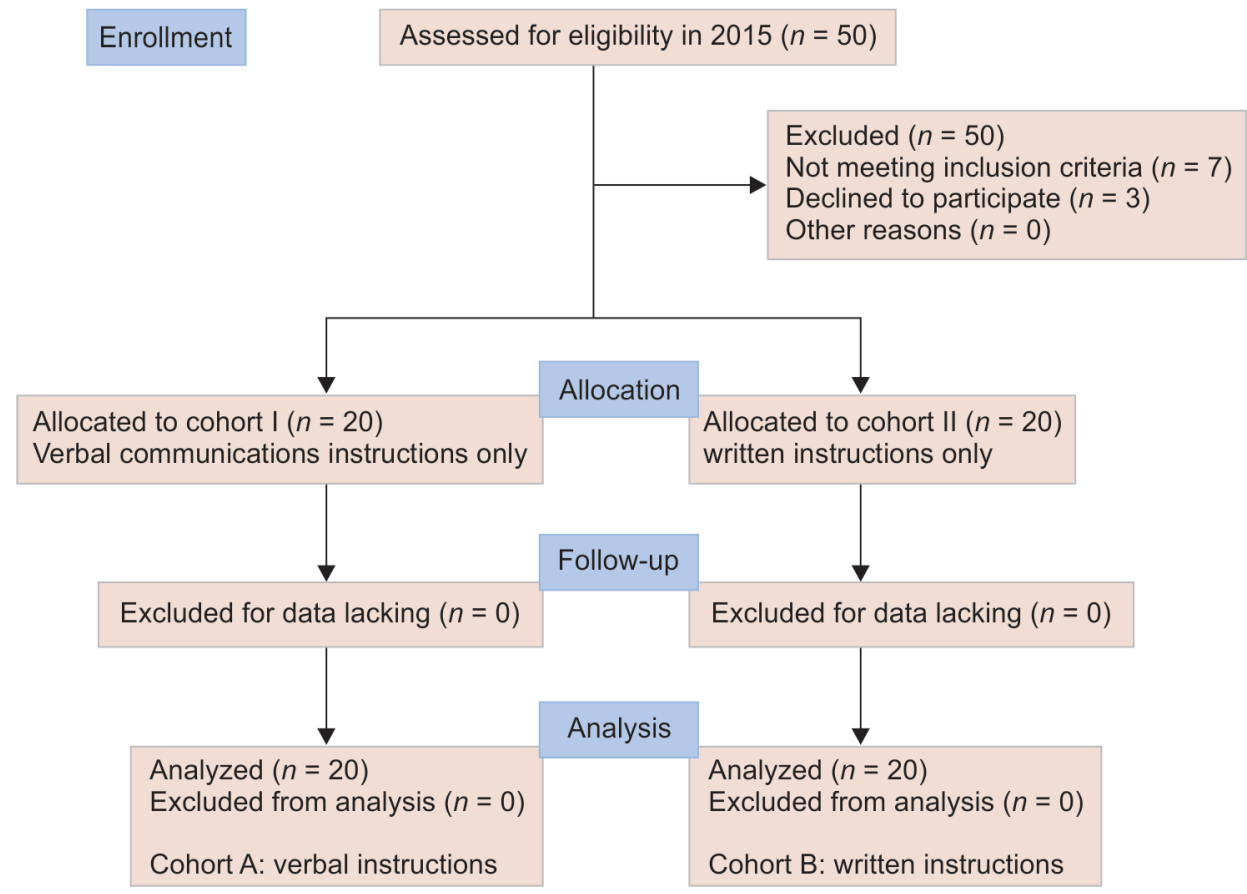



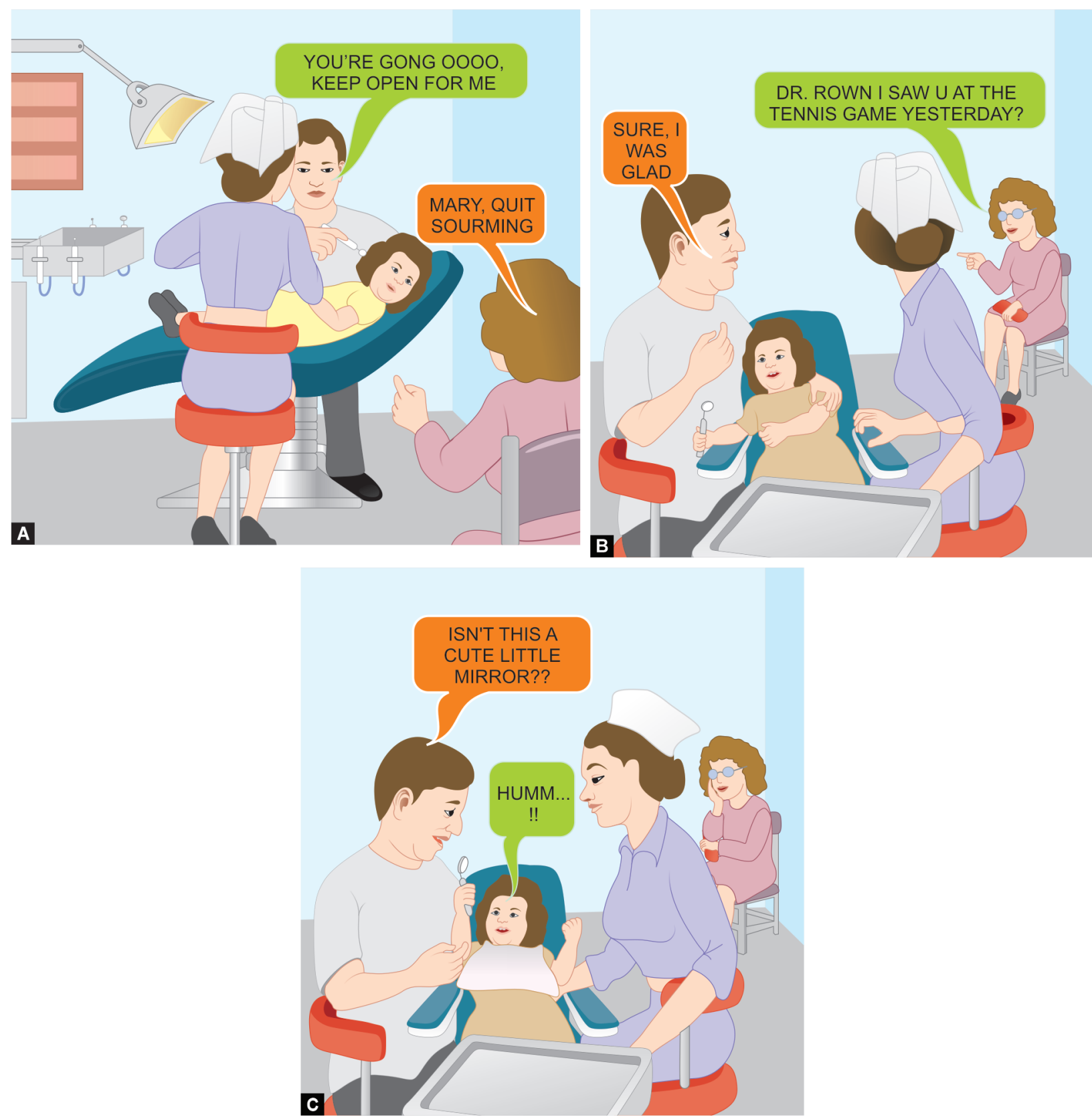

Figs $1 \mathrm{~A}$ to $\mathrm{C}$ : Illustrations used for recording the parents' response

procedures. The dentist utilized various behavioral management skills and had taken the help of one dental assistant throughout the research. All the research data were recorded by the dentist and the dental assistant. Additional data recorded included were age of the child on the day of treatment; restorative treatment provided at the time of interruption; and whether the parent's interruption was an attempt to speak with the dentist, child, or assistant.

The responding variable in this study was whether the parent interrupted the dental visit. Fisher's exact test was used to compare whether the interruption was associated with the type of caretakers. All data analysis were performed using SAS 9.2 software (SAS Institute, Inc, Cary, NC).

\section{Results}

The three types of responses were obtained at the end of the study: Response 1 where parents distracted the child by talking; Response 2 where parents distracts dentist by talking; and Response 3 where the parent was quiet and watching.

Most (72.5\%) parents remained silent in both the instruction groups. The verbal instructions-only group was slightly more compliant, with $85 \%$ parents remaining silent vs the written instruction-only group where $60 \%$ parents remained silent. This proportionate difference however was not significant ( $p$ value $=$ 0.189) (Fig. 2). 


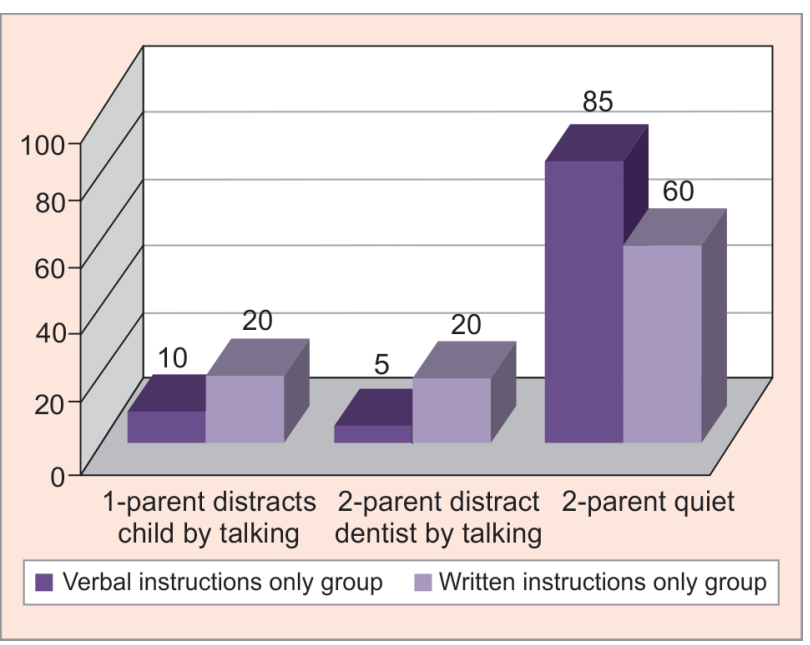

Fig. 2: Verbal instruction group vs written instruction group

Table 1: Comparison between verbal instruction group and written instruction group

\begin{tabular}{lllll}
\hline & Response 1 & Response 2 & Response 3 & Total \\
\hline Verbal instructions & 2 & 1 & 17 & 20 \\
only group & $10 \%$ & $5 \%$ & $85 \%$ & $100 \%$ \\
Written instructions & 4 & 4 & 12 & 20 \\
only group & $20 \%$ & $20 \%$ & $60 \%$ & $100 \%$ \\
\hline
\end{tabular}

Table 2: Responses for the verbal and written instructions only

\begin{tabular}{llll}
\hline & $\begin{array}{l}\text { Verbal instructions } \\
\text { only group }\end{array}$ & $\begin{array}{l}\text { Written instructions } \\
\text { only group }\end{array}$ & Total \\
\hline $\begin{array}{l}\text { Response 1- } \\
\text { Parents distracts } \\
\text { child by talking }\end{array}$ & 2 & 4 & 6 \\
$\begin{array}{l}\text { Response 2- } \\
\begin{array}{l}\text { Parents distracts } \\
\text { dentist by talking }\end{array}\end{array}$ & 1 & $66.7 \%$ & $15 \%$ \\
$\begin{array}{l}\text { Response 3- } \\
\begin{array}{l}\text { Parent is quiet } \\
\text { and watching }\end{array}\end{array}$ & 17 & 4 & 5 \\
\hline
\end{tabular}

In group I, verbal instruction-only group $(n=20), 10 \%$ parents had distracted child by talking, 5\% parent had distracted dentist by talking, and $85 \%$ parents were quiet and watching, whereas in group II, Written instructions-only group $(n=20), 20 \%$ parents had distracted child by talking, $20 \%$ parents had distracted dentist by talking, and $60 \%$ parents were quiet and watching (Table 1).

In Response I, parents distract the child by talking, 15\% parents had distracted the child by talking, where only $33.3 \%$ parents were given instructions verbally reinforced by the dentist and $66.7 \%$ parents were given written instructions by the dental assistant. In Response II, parents distracts dentist by talking, a total of $12.5 \%$ parents had distracted the dentist by talking among the $20 \%$ parents who were given instructions verbally and reinforced by the dentist and $80 \%$ parents were given written instructions by the dental assistant (Table 2).

In Response III, $72.5 \%$ parents were quiet and watchful, as they were instructed to be silent as a passive observer in the dental operatory among which $58.6 \%$ parents were given instructions verbally reinforced by the dentist and $41.4 \%$ parents were given written instructions by the dental assistant (Table 2). However, the abovementioned proportionate difference was not statistically significant ( $p$ value $=0.082$ ).

\section{Discussion}

A childhood fear is normal and part of child development. Young children's fear include fear of injury, separation from parents, and fear of the unknown. Dentists who advocate parental presence in the dental operatory suggest a positive influence of the parents by increasing the coping abilities of the young child in an unfamiliar environment. ${ }^{11}$

Since it is difficult to predict whether the child will cooperate better by the parental presence, Bauchner ${ }^{12}$ recommended that parents in general should be encouraged to be present to comfort their child during the restorative procedure. Traditionally, parental involvement during dental treatment was minimal; in fact, parental involvement was dynamically rejected by the dental staff. ${ }^{13}$ Medical healthcare providers also work meticulously with parents and use them as a support system in the treatment rooms of the hospital, oncology therapy suites, and even during anesthesia induction. The literature suggests that parents shows an overwhelming interest in accompanying children during stressful procedures. ${ }^{14,15}$ Pediatric dentists have expressed varying opinions on whether parents should be present in the operatory or not during their children's dental treatment. The goal of this study was not to debate for or against the parent existence in dental operatory but to advocate a way for the existence of parents may cast off as a benefit. Usually, the professionals decide on parent's participation in the process of treatment as well as patient managing judgments. Communication is the cornerstone of the process involved during treatment. Like every coin has two sides, parental presence may be disadvantageous sometimes.

The pediatric dentist also plays a role as a counselor, guide, teacher, and actor, thereby putting the skills to work for child and parent simultaneously which can be effective and efficient. Kamp suggested that choice should be given to the parents who want to accompany their child in the dental operatory. ${ }^{13}$ Studies indicate that most of the parents want to be with the child during treatment. ${ }^{13,14}$ Arathi stated that $66-78 \%$ of parents opted to be present in the operatory with their children. ${ }^{16}$ Majority of the parents feel the most important reason for their presence is their desire to see what happens to their children during the dental visit. ${ }^{14}$ Consequently, it becomes necessary for the pediatric dentist to maximize the advantages of parental attendance in the operatory while concomitantly reducing any negative effects by introducing the concept of the "silent" chair to parents while their child is receiving dental care. The parental presence resulted in dramatically lower heart rates, which suggests that parental presence composures the child in the form of reassurance. ${ }^{17}$

Most of the parents want to be present in the operatory during the treatment of their children and involve more actively during the treatment procedures. ${ }^{18}$ Parents should be present only with an uncooperative child because the calm patient does not need comforting, and when a parent is present it takes longer to treat the patient and thus production will be negatively affected. ${ }^{19}$ Parents usually have the best intentions when visiting the dental office with their child. ${ }^{20}$

The parents must remain "silent" and also not to create barriers to the rapport established between the child and the dentist. Hence, our study evaluated whether it was possible to follow the policy, 
first stated in the literature by Addelston, of a "silent chair". ${ }^{9}$ The parents need to see how their child responds to dental treatment and the need to keep informed of what happened during the visit and also, they wanted to inform about the procedure to the spouse. ${ }^{2}$ Wright stated that parental presence in the operatory and an active verbal manner results in negative consequences for the dentist-child relationship with the occurrence of the more uncooperative behavior. ${ }^{5}$ Molinari supported "silent chair" perspective by concluding that parents as submissive spectators can positively affect their child's treatment visit. ${ }^{21}$

The "silent chair" has the potential to increase the productivity of the dentist during an appointment due to the lack of disturbances created by the parent and may have a positive influence on a child's anxiety as well as behavior during dental care. ${ }^{15}$ Pediatric dentists have assumed that providing instructions for parents to remain as a silent observer while accompanying their children into the dental operatory will result in parental compliance, thus helping the dentist to facilitate care vs being a barrier to care. ${ }^{5}$ Implementation of the "silent chair" concept neither introduced any new risk nor required incremental resources from the practice such as incremental staffing and monetary funding that requires the motivation to follow it. The results of this study suggest that in routine clinical practice, where instructions provided to all parents to remain silent, it may be expected that the majority of parents will comply.

Maximum restorative care is required in 4-9-year-old children; therefore, we had selected this age-group range in our study. Research has been done in healthcare settings comparing compliance with instructions provided to patients in written form vs verbal instructions only. Written instructions have a positive impact on the effectiveness of patient teaching and also maximize patients' knowledge and adherence to treatment. ${ }^{16,22}$ Hoffmann ${ }^{22}$ stated that whenever written materials are designed for patients, they should be such that they are written simply and at the easy reading level to convey the information accurately. When the reading ability of the target group cannot be predetermined, a fifth- to sixth-grade reading level should be considered as an appropriate level for healthcare materials. The use of easier fonts and a minimum font size of 12 points was used in our study. Patients have also found the illustrations to be very effective, since illustrations make the material more attractive and therefore easier to read, and each illustration should convey a single idea.

In our study, those who were randomized to the verbal instructions-only group had higher rates of compliance with instructions than written instructions alone probably due to the dentist being a trustworthy authority figure for the parent which is consistent with previous study, suggesting that verbal instructions result in improved knowledge of treatment. ${ }^{16}$

A study by Jain evaluated the compliance of parents with instructions to remain silent in the dental operatory authors found that 32 of 39 parents remained silent as requested and 7 parents interrupted at least one time. They concluded that parents can still be expected to comply with instructions to remain silent and their compliance and presence would generally result in helping to facilitate care of the child. ${ }^{23}$ Rodriguez assessed healthy 3-9-yearold parents during the first restorative treatment and found that more parents were passive for written instruction than the verbal instruction group, and they concluded that asking parents to act as passive observers preserves advantages of parental presence in the operator while eliminating the disadvantages. ${ }^{24}$
The compliance rate in written instructions-only group was nearly $60 \%$, and the authors do not consider it clinically meaningful, as it was the subjective impression of the dentist and dental assistant that the visual illustrations used in the written instructions have been successful to capture the attention of the parents. Thus, the illustration use not only positively reinforces the written instructions but also improves compliance to remain a silent observer. Many factors may have contributed to a variance in parental compliance because our study population was from India. A similar study was done by Rodriguez, where only the treating dentist gave the preoperative instruction to be a passive observer, and it was not reinforced during treatment. The authors felt that reinforcing a request to be silent did not seem to encourage cooperation between the dentist and the parent, and the same dentist who treated the child was the only evaluator of the parent's compliance which may have introduced a degree of bias. ${ }^{24}$

The shortcoming of our study was that the sample size used was less; hence, further studies with larger sample size are recommended and also an association between parents interrupting the treatment and the age of the child was not assessed as the responses of parents of a 4-year-old and parent of a 9-yearold varies. Future studies should evaluate the effectiveness of using audiovisual illustrations along with written instructions to improve parental compliance vs written instructions only.

\section{Conclusion}

Based on this study's results, the conclusions made were parents did comply with instructions to remain a silent and also as a passive observer in the dental operatory effectively when provided either written or verbal instruction to do so during restorative treatment as a single preoperative instruction to the parents. If the parents are conformed, pediatric dentist could increase the efficiency and decrease time duration of the procedure.

\section{References}

1. Shahnavaz S, Rutley S, Larsson K, et al. Children and parents' experiences of cognitive behavioral therapy for dental anxiety - a qualitative study. Int J Paediatr Dent 2015;25(5):31. DOI: 10.1111/ ipd.12181.

2. Shroff S, Hughes C, Mobley C. Attitudes and preferences of parents about being present in the dental operatory. Pediatr Dent 2015;37(1):51-55.

3. D'Alessandro G, Alkhamis N, Mattarozzi K, et al. Fear of dental pain in Italian children: child personality traits and parental dental fear. J Public Health Dent 2015;76(3):179-183. DOI: 10.1111/jphd.12127.

4. Mahiepala NA, Phan VL, Kieu KD, et al. Influencing factors of paediatric dental anxiety levels in an undergraduate dental clinic. Eur J Paediatr Dent 2015;16(2):159-162.

5. Shellar B. Influence of the family. In behaviour management in dentistry for children Wright GZ, Kupietzky A John Wiley \& Sons; 2014. pp. 35-52.

6. Casamasimo PS, Wilson S, Gross L. Effect of changing US parenting styles on dental practice. perceptions of diplomates of the american board of pediatric dentistry. Pediatr Dent 2002;24:16-18.

7. Marcum B, Turner C, Courts F. Pediatric dentist's attitudes regarding parental presence during dental procedures. Pediatr Dent 1995;17(7):432-436.

8. Shaw O. Dental anxiety in children. Br Dent J 1975;3(4):134-139. DOI: 10.1038/sj.bdj.4803532.

9. Addelston HK. Child patient training. Fortn Rev Chic Dent Soc 1959;38:7-29. 
10. Me Laughlin G. SMOG grading: a new readability formula. J Read 1969;12:639-646.

11. Weinstein $P$, Nathan JE. The challenge of fearful and phobic children. Dent Clin North Am 1988;32(4):667-692.

12. Bauchner $\mathrm{H}$, Vinci R, Waring C. Pediatric procedures: do parents want to watch? Pediatrics 1989;84(5):907-909.

13. Kamp AA. Parent child separation during dental care: a survey of parent's preference. Pediatr Dent 1992;14(4):231-235.

14. Fenlon WL, Dabbs AR, Curzon ME. Parental presence during treatment of the child patient: a study with British parents. Br Dent J 1993;174(1):23-28. DOI: 10.1038/sj.bdj.4808062.

15. Pfefferle JC, Machen JB, Fields HW, et al. Child behavior in the dental setting relative to parental presence. Pediatr Dent 1982;4:311-316.

16. Arathi R, Ashwini R. Parental presence in the dental operatory: parent's point of view. J Indian Soc Pedod Prev Dent 1999;17(4):150155.

17. Pani SC, AlAnazi GS, AlBaragash A, et al. Objective assessment of the influence of the parental presence on the fear and behavior of anxious children during their first restorative dental visit. J Int Soc Prev Community Dent 2016;6(Suppl 2):S148-S152. DOI: 10.4103/22310762.189750 .
18. Heba JS, Ohoud TS. Parental preference for parental separation and their satisfaction regarding their children dental treatment in pediatric dental clinics in Saudi Arabia. J Int Soc Prev Community Dent 2020;10:116-123.

19. Kisby LE. Parental presence in the operatory: an update. Pediatr Dent J 2016;26(3):109-114. DOI: 10.1016/j.pdj.2016.07.004.

20. Nathan JE, Rayman MS, Golden BE, et al. Discretionary parental presence in the dental operatory: a survey of pediatric dentists and parents. Pediatr Neonatal Nurs Open J 2015;2(2):50-61. DOI: 10.17140/ PNNOJ-2-109.

21. Molinari G, DeYoung A. Parental presence and absence as behavior management techniques. J Mich Dent Assoc 2004;86(1):30-33.

22. Hoffmann T, Worrall L. Designing effective written health education materials: considerations for health professionals. Disabil Rehabi 2004;26(19):166-173. DOI: 10.1080/09638280410001724816.

23. Jain C, Mathu-Muju KR, Nash DA, et al. Randomized controlled trial: parental compliance with instructions to remain silent in the dental operatory. Pediatr Dent 2013;35(1):47-51.

24. Rodriguez HK, Webman MS, Arevalo O, et al. Passive observer instruction on parental satisfaction in a dental setting. J Clin Pediatr Dent 2018;42(5):339-343. DOI: 10.17796/1053-4625-42.5.3. 